\title{
Erythema Nodosum Manifestation Post COVID-19 Vaccine: A Case Report
}

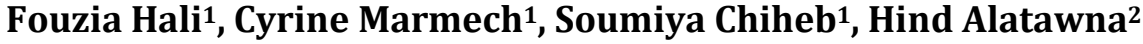 \\ ${ }^{1}$ Department of Dermatology and Venereology, Ibn Rochd University Hospital, Casablanca, Morocco \\ ${ }^{2}$ Pathology Center Ibn Zohr, Casablanca, Morocco \\ Email: cyrine.marmech1992@gmail.com
}

How to cite this paper: Hali, F., Marmech, C., Chiheb, S. and Alatawna, H. (2021) Erythema Nodosum Manifestation Post COVID19 Vaccine: A Case Report. World Journal of Vaccines, 11, 33-38.

https://doi.org/10.4236/wjv.2021.113005

Received: June 1, 2021

Accepted: July 27, 2021

Published: July 30, 2021

Copyright $\odot 2021$ by author(s) and Scientific Research Publishing Inc. This work is licensed under the Creative Commons Attribution International License (CC BY 4.0).

http://creativecommons.org/licenses/by/4.0/

\begin{abstract}
Erythema nodosum (EN) is a delayed hypersensitivity response that may be triggered by a range of conditions, including infections and vaccines. Rare cases of EN caused by COVID-19 were recently reported but none due to COVID-19 vaccines were documented. We report here a case of EN occurring after COVID-19 vaccination. Patient presented with painful nodular lesions of all 4 limbs, evolving for one month. These lesions appeared $48 \mathrm{~h}$ after the second dose of COVID-19 vaccination. The patient reported no recent infectious episodes. The physical examination found numerous, erythematous dermohypodermatitis knots with no palpable adenopathy. Some were regressive according to biligenesis shades. Biology and radiology findings eliminated other common causes of this dermatosis. The skin biopsy was done and suggested EN. The final diagnosis was post COVID-19 vaccine EN. Patient received a symptomatic treatment and had a slight improvement of the lesions 10 days after diagnosis. Physicians should be aware of the side effects of the vaccine including skin manifestations, especially since more people are bound to be vaccinated.
\end{abstract}

\section{Keywords}

Acute Hypodermitis, COVID-19, Erythema Nodosum, Hypersensitivity Response, Vaccine

\section{Introduction}

Erythema nodosum (EN) is a delayed hypersensitivity response that may be triggered by a range of conditions, including infection (mostly Streptococcus species) [1], medications, pregnancy, malignancies and inflammatory processes. First reported in late 2019, the COVID-19 has become a pandemic and has been 
mentioned in very few writing as an EN inducer [2] [3]. Some vaccines can also cause EN. The pathogenesis is unclear, but is considered a delayed hypersensitivity reaction triggered by exposure to an antigen [1]. This case is, to our knowledge, the first report of EN manifestation in the context of a COVID-19 vaccine. It seems likely that in 2021, COVID-19 vaccines will be globally available. Hence, we should be aware of their possible side effects

\section{Case Report}

A 66 years old female patient, with a breast cancer history since 2008 currently in remission, consulted for painful nodular lesions of the lower and upper limbs, evolving since one month. The investigation found the occurrence of EN 48 hours following the second injection of the "Astrazeneca" vaccine. The patient did not report any recent infectious episode. The physical examination found numerous, erythematous dermohypodermatitis knots of the 4 limbs. Some of them were regressive in appearance according to the biligenesis shades. Diameter ranged from 2 to $3 \mathrm{~cm}$ (Figure 1). There was no palpable adenopathy. Biology (Table 1) and radiology assessments consisting of CBC, CRP, ASO, transaminases, a fecal culture and chest radiography were done and had no pathological findings except an elevated ESR. Hepatitis B and C serology were negative.

The skin biopsy showed fibrosing septal hypodermitis without vascular involvement associated with a minimal dermohypodermal granulomatous infiltrate suggesting an EN (Figure 2).

The patient received a symptomatic treatment consisting of Vitamin C, antihistaminic, emollient and dermocorticoids. 10 days after initial diagnosis, the patient had a slight improvement of the lesions (Figure 3).

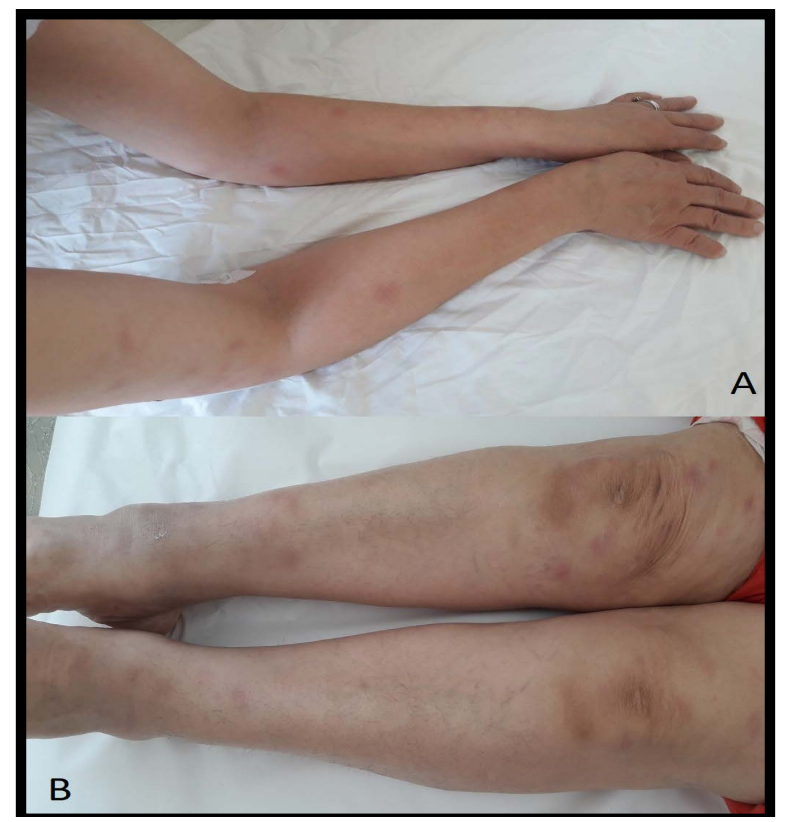

Figure 1. Aspect of EN at admission (A: upper limbs/B: lower limbs). 


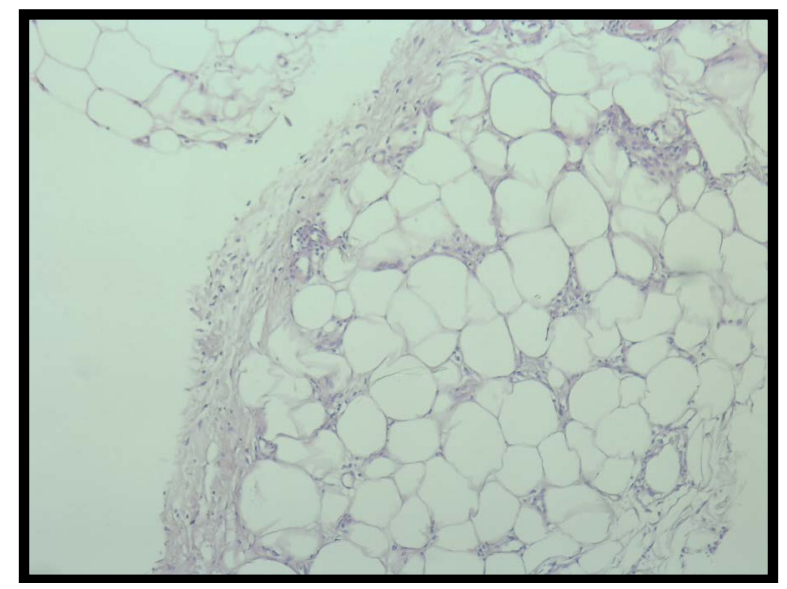

Figure 2. Fibrosing septal hypodermitis (HE stain/magnification: $\mathrm{x} 40$ ).

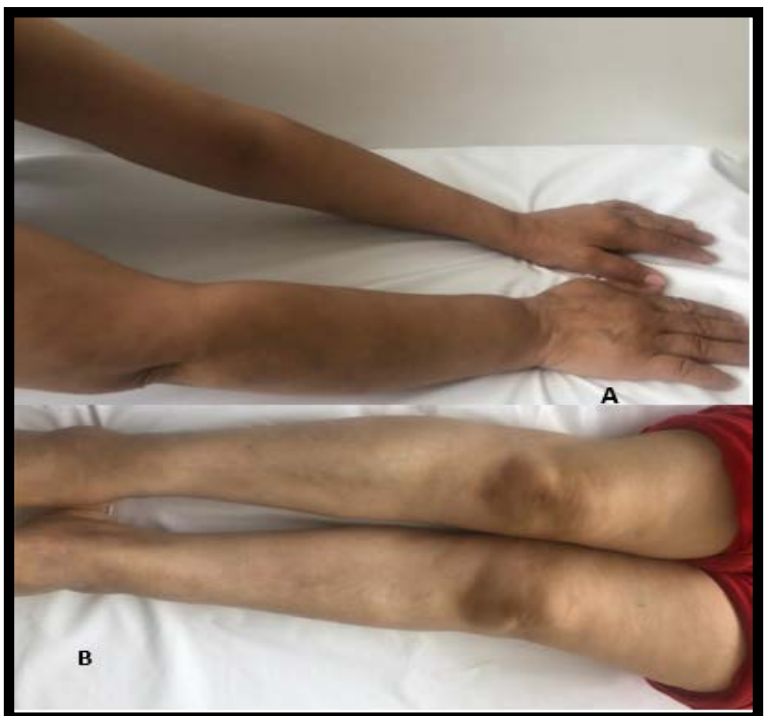

Figure 3. Aspect of EN 10 days after treatment.

Table 1. Biological analyzes.

\begin{tabular}{cccccc}
\hline CBC & CRP & ESR & SGPT & SGOT & ASLO \\
\hline Hemoglobin: 12 & & & & & \\
Leucocytes: 5000 & & & & & \\
Neutrophils: 2850 & 5 & 92 & 10 & 16 & 190 \\
Eosinophils: 50 & & & & & \\
Lymphocytes: 1700 & & & & & \\
Platelets: 270,000 & & & & & \\
\hline
\end{tabular}

\section{Discussion}

Erythema nodosum (EN) is the most frequent clinical form of acute hypodermitis in young women with a mean age around 20 to 40 years [4] [5] [6]. In our case, the apparition of EN is late onset at 66 years old. The typical manifestations of EN are erythematous, painful, bilateral nodules on the lateral sides of the ex- 
tremities, especially the lower limbs [2]. In our observation, the symptomatology involved all 4 limbs which make our case special.

EN usually resolves spontaneously within 8 weeks [1]. The diagnosis is usually clinical but in some doubtful cases, a biopsy may be required [7]. Independently of etiology, EN is characterized by typical histological features: inflammation of the dermohypodermic junction and the periphery of the septa, containing neutrophils and eosinophils, turning to an infiltrate of lymphocytes and histiocytes as the process evolves, which is in concordance with our case. Histiocytic granulomas, known as Miescher's radial granulomas, can also be found [6].

The assessment made in our case aims to eliminate the most frequent causes of this dermatosis, which are haemolytic streptococcal infections, sarcoidosis and bacterial or inflammatory enteropathies.

In $15 \%$ - $50 \%$ of cases of EN, the etiology remains undetermined.

The imputability of a drug, when it is evoked, is difficult to prove.

Some vaccines can induce EN, such as BCG, hepatitis B or typhoid fever vaccines [8] [9]. Rare cases mentioned a vaccine against HPV as an EN inducer [10] [11].

In our patient, recent vaccine administration is the trigger for EN. To the best of our knowledge no previous association between EN and COVID-19 vaccine has been reported.

The pathogenesis of EN is unclear, but is considered a delayed hypersensitivity reaction triggered by exposure to an antigen. In this observation, the lesions appeared 48 hours after vaccination, which is in line with the hypothesis cited above.

In fact, some vaccines introduce a mild infection that resembles the real infection, leading to a strong immune response [12].

COVID-19 infection can lead to a deregulated immune response. Rare cases of EN have been recently described in association with COVID-19 [2] [3].

Certain inflammatory markers are increased in COVID-19 such as IL-1, -2, -6, -7 , and -10 [13] [14]. In patients with EN, polymorphisms of IL-1 and -6 promoter genes have been described [15] [16], as well as high levels of IL-6 [17]. This may result in a higher susceptibility to EN in situations of immune dysregulation, like COVID-19, thus resulting in an excessive inflammatory reaction. This might partly clarify the connection between COVID-19 and EN.

\section{Conclusion}

We reported here a unique case of EN occurring after COVID-19 vaccination. As the state of the pandemic is quickly evolving, more people are bound to get vaccinated. Thus, clinicians should be mindful of the side effects of the COVID-19 vaccines including skin manifestations. Literature is likely to reveal more dermatological manifestations in the future.

\section{Conflicts of Interest}

The authors declare no conflicts of interest regarding the publication of this paper. 


\section{References}

[1] Schwartz, R.A. and Nervi, S.J. (2007) Erythema Nodosum: A Sign of Systemic Disease. American Family Physician, 75, 695-700.

[2] Ordieres-Ortega, L., Toledo-Samaniego, N., Parra-Virto, A., Fernández-Carracedo, E., Lavilla-Olleros, C. and Demelo-Rodríguez, P. (2020) Atypical Erythema Nodosum in a Patient with COVID-19 Pneumonia. Dermatologic Therapy, 33, e13658. https://doi.org/10.1111/dth.13658

[3] Suter, P., Mooser, B. and Thien, H.P. (2020) Erythema Nodosum as a Cutaneous Manifestation of COVID-19 Infection. BMJ Case Reports, 13, e236613. https://doi.org/10.1136/bcr-2020-236613

[4] Cribier, B., Caille, A., Heid, E. and Grosshans, E. (1998) Erythema Nodosum and Associated Diseases. A Study of 129 Cases. International Journal of Dermatology, 37, 667-672. https://doi.org/10.1046/j.1365-4362.1998.00316.x

[5] Blake, T., Manahan, M. and Rodins, K. (2014) Erythema Nodosum-A Review of an Uncommon Panniculitis. Dermatology Online Journal, 20, 22376. https://doi.org/10.5070/D3204022376

[6] Requena, L. and Yus, E.S. (2008) Erythema Nodosum. Dermatologic Clinics, 26, 425-438. https://doi.org/10.1016/j.det.2008.05.014

[7] Rachadi, H., Ramli, I., Senouci, K., Hassam, B. and Ismaili, N. (2015) Érythème noueux induit par l'imatinib: Un cas confirmé par une épreuve de réintroduction positive. Annales de Dermatologie et de Vénéréologie, 142, S694. https://doi.org/10.1016/j.annder.2015.10.568

[8] Goolsby, P.L. (1989) Erythema Nodosum after Recombivax HB Hepatitis B Vaccine. The New England Journal of Medicine, 321, 1198-1199.

https://doi.org/10.1056/NEJM198910263211717

[9] Thomson, B.J. and Nuki, G. (1985) Erythema Nodosum Following Typhoid Vaccination. Scottish Medical Journal, 30, 173. https://doi.org/10.1177/003693308503000310

[10] Doffoel-Hantz, V., Hantz, S., Souyri, N., Nouaille, Y., Bédane, C. and Sparsa, A. (2009) Erythème Noueux Induit par le Gardasil ${ }^{\circledR}$. La Revue de Médecine Interne, 30 , S131-S132. https://doi.org/10.1016/j.revmed.2009.03.291

[11] Longueville, C., Doffoel-Hantz, V., Hantz, S., Souyri, N., Nouaille, Y., Bédane, C., et al. (2012) Érythème Noueux Induit par le Gardasil ${ }^{\circledR}$. La Revue de Médecine Interne, 33, e17-e18. https://doi.org/10.1016/j.revmed.2011.02.013

[12] Wang, J., Peng, Y., Xu, H., Cui, Z. and Williams, R.O. (2020) The COVID-19 Vaccine Race: Challenges and Opportunities in Vaccine Formulation. AAPS PharmSciTech, 21, Article No. 225.

https://www.ncbi.nlm.nih.gov/pmc/articles/PMC7405756/

https://doi.org/10.1208/s12249-020-01744-7

[13] McGonagle, D., Sharif, K., O’Regan, A. and Bridgewood, C. (2020) The Role of Cytokines Including Interleukin-6 in COVID-19 Induced Pneumonia and Macrophage Activation Syndrome-Like Disease. Autoimmunity Reviews, 19, Article ID: 102537. https://doi.org/10.1016/j.autrev.2020.102537

[14] Prompetchara, E., Ketloy, C. and Palaga, T. (2020) Immune Responses in COVID-19 and Potential Vaccines: Lessons Learned from SARS and MERS Epidemic. Asian Pacific Journal of Allergy and Immunology, 38, 1-9.

[15] Amoli, M.M., Miranda-Filloy, J.A., Vazquez-Rodriguez, T.R., Ollier, W.E.R. and Gonzalez-Gay, M.A. (2011) Interleukin-1 Beta Gene Polymorphism in Patients with 
Biopsy-Proven Erythema Nodosum. Clinical and Experimental Rheumatology, 29, S131-S132.

[16] Amoli, M.M., Miranda-Filloy, J.A., Fernandez-Diaz, M.L., Martin, J., Ollier, W.E.R. and Gonzalez-Gay, M.A. (2008) Interleukin-6 Promoter Polymorphism at Position -174 in Biopsy-Proven Patients with Erythema Nodosum from a Defined Population. Clinical and Experimental Rheumatology, 26, S155-S156.

[17] De Simone, C., Caldarola, G., Scaldaferri, F., Petito, V., Perino, F., Arena, V., et al. (2016) Clinical, Histopathological, and Immunological Evaluation of a Series of Patients with Erythema nodosum. International Journal of Dermatology, 55, e289-e294. https://doi.org/10.1111/ijd.13212 